\title{
Infancia alterada en pleitos por la custodia de menores
}

Marcela Jabbaz Churba

Universitat de València

ALTERED CHILDHOOD IN CHILD CUSTODY LAWSUITS

Resumen

En este artículo se analizan las disputas entre madres y padres por la custodia y el régimen de visitas de sus hijos e hijas, mediante una interpretación de sus narrativas. Se focaliza en los casos donde el divorcio es conflictivo, evidenciándose una presencia importante de formas de violencia de género, con y sin denuncia. A través de relatos, analizo la situación previa, el proceso judicial y las relaciones entre la expareja una vez que se han tomado las medidas judiciales definitivas con relación a las criaturas. En cada momento del proceso judicial se identifican y analizan elementos nodales pero poco visibles: en la situación inicial, la incertidumbre vivida por la ausencia de normas de convivencia. Luego, las dificultades que plantean los rituales judiciales para evidenciar situaciones complejas y el dilema de las madres sobre si informar o no de los malestares que pueden sufrir sus criaturas porque temen no ser creídas. Finalmente, la emergencia de nuevos tipos de violencia encubierta, como el abuso económico vinculado a las pensiones y el acoso de custodia. Los divorcios en los que el conflicto se vuelve crónico pueden alterar la vida cotidiana de las criaturas.

Palabras clave

Custodia compartida; interés superior del menor; acoso de custodia; estudios de género; tribunales de familia; violencia de género

Códigos JEL: K15, K36, K38,K41
Abstract

In this article, the disputes of mothers and fathers about the custody and visitation of their sons and daughters are analyzed, through an interpretation of their narratives. It focuses on cases where divorce is conflictive, evidencing a significant presence of forms of gender-based violence, with and without a judicial complaint. Through stories, I analyzed the previous situation, the judicial process and the relations between the ex-partner once the definitive judicial measures had been taken in relation to the children. Nodal but not very visible elements are identified and analyzed at each moment of the judicial process: in the initial situation, the uncertainty experienced by the absence of rules of coexistence. Then, the difficulties posed by judicial rituals in showing complex situations and the mothers' dilemma about whether or not to report the inconvenience their children may suffer for fear that they will not be believed. Finally, the emergence of new types of covert violence, such as financial abuse related to pensions and custody harassment. Divorces in which conflict becomes chronic can disrupt children's daily lives.

Keywords

Joint custody; best interests of the child; custody harassment; gender studies; family court; gender-based violence

JEL codes: K15, K36, K38,K41

Fecha de recepción del original: 18 de enero de 2021; versión definitiva: 3 de agosto de 2021.

Marcela Jabbaz Churba, Universitat de València. Institut Universitari d'Estudis de la Dona, Carrer del Serpis 29, $4^{\circ}$ -

Edifici Beatriu Civera, (46022) València.

Tel.: +34 963983795; E-mail: Marcela.Jabbaz@uv.es: ORCID ID: https://orcid.org/0000-0002-7755-7742. 


\title{
Infancia alterada en pleitos por la custodia de menores
}

\author{
Marcela Jabbaz Churba
}

Universitat de València

\section{Introducción}

Las narrativas de madres y padres que disputan judicialmente la custodia de sus hijos e hijas son el material empírico que se analiza en este artículo. Estas narrativas reflejan sus percepciones sobre el entramado institucional en el cual se introducen cua ndo deciden litigar judicialmente, y nos permiten conocer las repercusiones que tienen en sus vidas las decisiones judiciales que allí se toman. También se recogen sus relatos respecto a cómo se desenvuelven sus relaciones interpersonales con posterioridad a la sentencia sobre el régimen de custodia y visitas relativo a las criaturas que se tienen en común. El objetivo del estudio es, por un lado, en el ámbito institucional, dilucidar lo que se pone en juego en las distintas etapas del proceso judicial y, por otro lado, con posterioridad a la sentencia de divorcio y en el ámbito familiar, identificar los mecanismos de control y violencia, que resultan invisibles para la justicia, como el abuso económico y el acoso de custodia. Infancia alterada es el título de este artículo por la discrepancia que existe entre el ideal de niñez como etapa feliz, de protección y de cuidados, y los efectos que los procesos descritos producen en niños, niñas y adolescentes que participan, sin voz ni poder de decisión, del conflicto y del ejercicio del poder, en el ámbito familiar y judicial.

Cabe señalar que si bien este estudio no fue inicialmente sobre violencia de género, en muchas situaciones, y esta es una más, resulta indeterminada su incidencia ya que la mayor parte de mujeres que la sufren no la denuncian'. Pero en virtud de haber focalizado el análisis en divorcios litigiosos, obtuvimos indicios importantes de violencia de género, sobre todo violencia económica y psicológica y, mediante éstas, un ejercicio sobre la mujer, pero también sobre los hijos e hijas que se tienen en común y que hoy se denomina como violencia vicaria.

Otra cuestión a señalar sobre nuestra investigación es que nos apartamos parcialmente del debate legal, porque

\footnotetext{
1 Según datos de la Macroencuesta de Violencia contra la Mujer (Ministerio de Igualdad, 2019) solo el $21,7 \%$ de las mujeres que han sufrido violencia física, sexual o emocional de alguna pareja actual o pasada ha denunciado.
}

nuestro énfasis en la indagación es conocer cómo las decisiones judiciales encierran criterios morales y éticos al valorar las formas de convivencia sobre las cuales han de tomar decisiones (Hacker 2008). De este modo, veremos que la judicatura y la fiscalía asignan, alternativamente y en diferentes circunstancias, una importancia variable a los intereses psicológicos, materiales, educativos o médicos de los niños y niñas, o pueden tomar sus decisiones tendiendo a valorar el presente o tendiendo a privilegiar el futuro. Existen estudios que indican que el razonamiento judicial está también muy condicionado por las tradiciones judiciales (Hunter, 2015) y que se producen exclusiones para quienes se apartan de las mismas.

Desarrollo aquí la tesis de que existen interrelaciones y condicionamientos entre los ámbitos institucional y privado que producen una judicialización de la vida y un círculo vicioso del que resultan unas maternidades amenazadas. Por un lado, ambas partes del conflicto por la custodia demandan a la autoridad judicial que ponga orden en unas relaciones privadas que no logran por sí mismos auto-regular. Iniciar un procedimiento legal modifica sustancialmente las relaciones interpersonales de la expareja porque entran en un proceso de burocratización y pierden espontaneidad, porque cualquier elemento (correo electrónico, registro médico o escolar, WhatsApp) puede convertirse en una prueba, y así hemos visto que se los exigen sus abogados/as. Entonces, hay un cambio cualitativo en los vínculos que se vuelven impostados. Por otro lado, los veredictos judiciales suelen no resolver una disputa interpersonal que en sí misma puede ser irresoluble. En la superficie aparecen las disputas en torno a las criaturas y la cuestión patrimonial. Pero a ello, en los conflictos analizados, se suman cuestiones implícitas vinculadas a un cambio en los equilibrios de poder en las relaciones de género debido a la ruptura. Aparece un cierto malestar masculino vinculado en mayor o menor medida a una pérdida de poder y control sobre la mujer cuando se produce la separación y a un sentimiento de padre desplazado, vinculado a un menoscabo de su posición en la familia.

Cuando hay violencia de género, con o sin denuncia, este malestar se traduce, como veremos, en un conflicto crónico. Hay una sentencia judicial, pero esta sentencia no representa el final del conflicto sino que éste sigue por otros medios, y se filtra por resquicios y cuestiones no re- 
guladas, dilatando lo que de todos modos se tiene que cumplir, por ejemplo, el pago de la pensión. Mediante malas palabras, extorsión afectiva con los hijos e hijas y todo tipo de mecanismo, se hace un uso inescrupuloso del derecho de patria potestad de modo tal de retener poder de decisión sobre la vida de las criaturas, representando también un mecanismo de control simbólico sobre las madres.

Watson y Ancis (2013) identificaron situaciones de abuso económico relacionadas con las pensiones y, en general, el manejo del dinero. Y Elizabeth (2017) un acoso de custodia por el cuestionamiento de múltiples decisiones cotidianas asumidas por las madres. Se trata de unos tipos de violencia propios de estas situaciones de ruptura cuando hay violencia de género (con o sin denuncia), que producirán un cuestionamiento sobre la autoridad maternal y una amenaza latente sobre la continuidad de la convivencia con sus hijos e hijas.

\section{Metodología}

Esta investigación fue realizada por encargo del Pacto Valenciano contra la Violencia de Género y sus resultados se exponen en el libro Menores en disputa. Custodia, visitas y patria potestad en la Comunidad Valenciana (JabbazChurba y Díaz-Martínez, 2020). En este artículo presento reflexiones teóricas posteriores y una reelaboración del material empírico. El enfoque del estudio es cualitativo y se basa en el análisis de percepciones subjetivas sobre la realidad (Alonso, 2013). Por lo tanto, no se trata de mostrar una verdad sino de interpretar el filtrado que sujetos insertos en tramas complejas de relaciones estructuradas producen en función de su propia historia, cultura y condicionamientos sociales. Ello nos permite entender el sentido de las acciones que emprenden frente situaciones concretas de ámbito familiar e institucional. A diferencia de la justicia -que al mismo tiempo que interpreta las subjetividades en conflicto ha de decidir sobre el entorno más favorable para las y los menores-, el enfoque aquí utilizado se limita a comprender las distintas lógicas y los nudos y problemas resultantes de los encuentros y desencuentros entre las y los actores sociales significativos.

Se utilizaron varias fuentes y técnicas de producción y recopilación de datos (Jick, 1979; Morgan,1983) y la investigación se desarrolló en diferentes niveles: estadísticas de organismos oficiales relativas a divorcio y violencia de género, entrevistas semi-estructuradas, consultas a personas expertas y observación directa.

La muestra se definió como mujeres y hombres en parejas heterosexuales que disputan la custodia de sus hijos/ as en los tribunales ${ }^{2}$. Por tanto, los resultados de esta investigación no son válidos para rupturas donde existe un acuerdo entre la expareja en torno a la forma de conviven-

\footnotetext{
2 Según datos del Consejo General del Poder Judicial de 2017, en España los casos con litigios por la custodia de los hijos representan el 20,1\%, frente al $79,9 \%$ que son de mutuo acuerdo.
}

cia posterior a la ruptura. No obstante, esta delimitación ha sido difícil ya que el mutuo acuerdo, en ocasiones, se vio artificialmente inducido por las abogacías que negocian entre sí y promueven una aceptación, no siempre convencida, por parte de sus representados. Por tanto, hemos tenido en cuenta también estos matices donde el acuerdo puede ser artificial y, por lo tanto, deslizante y transitorio.

No se entrevistó a parejas, sino a 18 madres y 15 padres que no mantenían vínculos entre sí. El criterio de inclusión fue que se tratara de casos litigiosos y que estuvieran en el periodo 2011-2017, desde que se promulgó la Ley 5/2011, de 1 de abril, conocida como «de custodia compartida impuesta» en la Comunidad Valenciana, hasta un año después de su derogación (momento en que realizamos el trabajo de campo). Luego se buscó incluir la máxima diversidad de casos en relación al nivel socioeconómico, ocupaciones, cantidad y edad de las criaturas ${ }^{3}$. También se realizaron entrevistas al personal técnico, dos de éstas en Puntos de Encuentro Familiar (PEF) y dos en los Centros Mujer 24 horas.

Además, consultamos a personas expertas mediante la técnica Delphi: jueces, fiscales, abogados, psicólogos forenses, profesionales de servicios de apoyo como los puntos de encuentro familiar y de atención a víctimas de violencia de género. Realizamos dos rondas de consulta a las personas expertas. Para la primera ronda, se elaboró un cuestionario destinado a contrastar cuestiones clave identificadas en las entrevistas a madres y padres. Los cuestionarios se enviaron y recibieron por correo electrónico a las 17 personas a quienes previamente habíamos contactado por teléfono y comprometido a participar. El cuestionario de la segunda ronda de consultas se centró en las discrepancias encontradas en la primera ronda. La intención no era que llegaran a un consenso, sino profundizar en las reflexiones.

Finalmente, se realizaron observaciones directas en servicios de atención a víctimas de violencia de género y puntos de encuentro familiar.

El análisis siguió el método de la "teoría fundamentada" (Glaser y Strauss, 1967) mediante el cual las narrativas son interpretadas a la luz de categorías teóricas previas, pero también mediante otras categorías (temas y subtemas) que emergen del material empírico y de las notas de campo. La interpretación es, en síntesis, un proceso de deconstrucción y reconstrucción del material empírico en forma de pirámide. En la base disponemos de centenares de páginas de narrativas y descripciones, de las que se van extrayendo categorías que intentan interpretar el fenómeno bajo análisis.

El análisis se realiza en cuatro momentos clave: 1) la situación inmediatamente anterior a la celebración del juicio: un momento de anomia en el que no hay pautas en común respecto de las criaturas $y$, por tanto, está caracterizado por sufrimiento, temores y una gran incertidumbre; 2) el primer juicio en el que se dictan las medidas provisionales: el papel del informe psicosocial y donde se manifiesta el dilema de las madres (Elizabeth et al., 2010); 3) las

\footnotetext{
${ }^{3}$ La guía de entrevistas, los cuestionarios y los detalles relativos a la muestra de personas entrevistadas pueden verse en https://www.uv.es/marijab/ANEXOS. pdf.
} 
Tabla 1. Separaciones y divorcios de parejas heterosexuales según sea de mutuo acuerdo o contencioso y el sexo de quién presente la demanda, España 2017

\begin{tabular}{|l|r|r|r|r|r|r|r|r|}
\hline & \multicolumn{2}{|c|}{ Total } & \multicolumn{2}{c|}{ Esposo } & \multicolumn{2}{c|}{ Esposa } & \multicolumn{2}{c|}{ Ambos cónyuges } \\
\hline Mutuo acuerdo & 78.331 & $100 \%$ & 4.063 & $5 \%$ & 7.218 & $9 \%$ & 67.051 & $86 \%$ \\
\hline Contencioso & 22.847 & $100 \%$ & 7.850 & $34 \%$ & 14.785 & $65 \%$ & 212 & $1 \%$ \\
\hline
\end{tabular}

Fuente: elaboración propia en base a datos del CGPJ - INE.

medidas definitivas, con rituales judiciales de respuestas cortas y específicas que dificultan contar la propia historia (un proceso complejo y no hechos inconexos), y el doble rasero (Eichler, 1991) aplicado a madres y padres cuando se argumenta sobre la capacidad del progenitor para cuidar, y 4) la situación post-judicial donde observamos un círculo vicioso en torno al abuso económico y el acoso de custodia que devendrá en una situación de maternidades amenazadas.

\section{La situación previa y el inicio de la judicialización}

En la mayoría de los casos, quienes inician la demanda judicial en lo que serán divorcios conflictivos son mujeres. Así lo registra el Consejo General del Poder Judicial (tabla 1), siendo la esposa quien lo inicia en el $65 \%$ de los casos contenciosos.

No se trata aquí de analizar cuáles fueron las razones de la ruptura sino entender qué es lo que sucede para que, más allá de la impronta que puede producir en una persona la situación de ruptura, ésta se torne en litigiosa. Comenzamos preguntando, entonces, sobre cómo fue apareciendo el conflicto abierto en torno a la custodia y las razones por las que deciden poner una demanda judicial en vez de acordar un convenio regulador. Las razones giraron, inicialmente, alrededor de la imposibilidad de llegar a acuerdos sobre los desplazamientos de los hijos e hijas entre las residencias del padre y la madre.

«La niña ya tenía 11 meses, era lactante y nunca había dormido con él y un día me mandó un mensaje y me dijo "hoy se queda a dormir conmigo". Cada vez que se la llevaba, porque yo no le podía decir que no se la llevara, porque mi abogada me decía que no podía, cada vez, era la incertidumbre de no saber si me la devolvía o no. A la noche me decía "me la quedo yo por 2 días", entonces para mí era un sinvivir, yo temblaba cada vez que se la llevaba» (Estela).
Estela deseaba acordar con el padre de la niña un sistema de visitas, pero tuvo que recurrir a la justicia. Y ellos también se quejan de que les limitan las visitas:

Ella lo cogía como excusa, como que yo la estaba acosando. Yo iba a la puerta del colegio con todo el mundo y en un juicio lo sacó a relucir, que yo iba a la puerta del colegio, o al futbol y que me alteraba ahí. Claro que me alteraba!, si yo quería ver a mis hijos, no quería buscarla a ella. No me dejaba verlos, pero en ningún momento agredí a nadie, ni nada de nada (Iñaki).

Ella no me lo dejaba ver, el niño tenía tres años, yo le llamaba diciéndole que quería verlo y nunca estaba, desde que me fui. Como yo soy de una manera que tampoco veía a mi hijo, no montaba bulla, no voy a ponerme a gritar. Si no lo veo, no lo veo. Como al mes, ahí fue cuando ella me llamo y me dijo que fuera a verlo y que me quedara con el niño (Bernardo).

En el análisis del conjunto de los casos, hemos observado que la incertidumbre en este periodo es una constante. También que su duración es variable y aleatoria: primero, el tiempo de demora hasta tomar la decisión de visitar al abogado o abogada, luego que éste presente la demanda de divorcio o, en su caso, las medidas extramatrimoniales para el mismo fin. Luego se ha de esperar otro lapso variable para que den la cita en el juzgado. En el caso de Estela fueron 10 meses, casi un año de incertidumbres en torno a la criatura desde que comunicó a su expareja la separación hasta que se celebró el juicio de medidas provisionales y se estableció un régimen de visitas que, entonces sí, dieron previsibilidad a las recogidas y devoluciones de la bebé.

El caso de Luz es un buen ejemplo del proceso de judicialización del vínculo interpersonal: pasaron a relacionarse solo mediante correos electrónicos y de tutearse a dirigirse al Señor o a la Señora y el apellido. Luz nos entregó dos carpetas repletas de correos electrónicos y WhatsApp que se enviaron entre la expareja y entre el padre y sus hijos/as. La judicialización amplificó la desconfianza que previamente sentían entre ambos, sumando a la propia, la de sus abogados/as.

En otros casos, la dependencia emocional de una de las partes o de ambas, lleva a intentos de recomposición, que por lo que hemos visto en las entrevistas, a menudo empeoran la situación. 
«Luego fue un error, pero si no lo intentas por él [por el niño], no vas a ninguna parte. Entonces retomamos otra vez la relación, intentamos llevarlo bien, un tiempo bien y luego, otra vez, escaleras abajo. Ella otra vez con sus problemas de pastillas anti depresivas, y siempre ha tomado alcohol. Yo nunca he tomado alcohol, nada (Gerard).

Hay muchos envites y cuando no se obtiene lo que se desea, al no estar regulada la visita y la comunicación con las y los menores, en ocasiones, se les puede dañar al colocarlos en medio del conflicto entre sus padres, sobre todo antes de la adolescencia, cuando aún no tienen suficiente autonomía y las figuras de autoridad, materna y paterna, no han sido cuestionadas. Pueden convertirse en «moneda de cambio»y amenazas:

"Él me decía: si no haces lo que te digo, entonces, no les puedes llamar mientras están en mi casa o no autorizo tal cosa" (Celia).

Este tipo de chantaje aparece sobre todo antes de que esté regulado el régimen de custodia y visitas, pero si hay conflicto, puede mantenerse hasta que los hijos e hijas se independizan (mucho después de la sentencia judicial).

La regulación mediante una sentencia judicial resulta fundamental porque permite contar con unos parámetros en función de los cuales ajustar la relación en una pareja que no puede establecer normas de convivencia por sí misma. Pero, lamentablemente, no todo puede ser previsto y regulado, ya que siempre se presentan necesidades y situaciones nuevas. Entonces, por los resquicios de las reglas establecidas en convenios y sentencias, es decir, por los aspectos menos previsibles y controlados, se cuela nuevamente el chantaje y el conflicto entre la expareja. En algunos casos, de bajos recursos económicos, se planteó continuar la convivencia post-anoticiarse de la decisión de separación.

«Estuvimos desde el mes de junio que empezamos el trámite hasta el 12 de enero [7 meses] conviviendo en casa con los niños, igual fue una estrategia... Después alegó en las provisionales que estábamos haciendo una custodia compartida y, para no cambiar, dictaron entonces custodia compartida. Pero lo que sucedía era que no se había ido de la casa. Luego se alquiló un piso enfrente desde donde controla todo» [no hay denuncia de violencia de género, pero ella vive atemorizada. Por este motivo no quiso hacer la entrevista en su domicilio] (Ana).

La convivencia bajo el mismo techo, porque aún no se ha establecido legalmente quién se queda en el domicilio familiar, degrada aún más los vínculos, y entraña el riesgo de vivir agresiones cotidianas. En estos casos, pero también en otros, se plantearon temores vinculados con la seguridad personal.

«Cuando él venía a recogerla yo necesitaba estar acompañada y si no había nadie en la casa, hablaba sola como si hubiera alguien, me sentía más segura. Enton- ces comencé a ir con la terapeuta y fue quien me dijo, claramente, cuando comenzamos a analizar la relación, que habíamos tenido una relación de violencia psicológica» (Adela).

«Yo buscaba seguridad, porque la situación violenta era fuerte y la amenaza que sentía sobre mi hijo también. Si no, me hubiera escapado... pero encontré mucha ayuda, en la Casa de la Dona, en mis padres... y así comencé, primero con la separación civil» (Verónica).

En los casos de Adela y Verónica, el temor vivido las llevó a iniciar un proceso de divorcio, y recién luego interpusieron una denuncia penal por violencia de género. En el caso de Verónica esta última no prosperó porque, según se nos relató, su exmarido alegó enfermedad mental.

La prolongación del periodo entre la decisión de la separación (y su comunicación al otro) y el establecimiento de medidas reguladoras de la convivencia, sea por negligencia de las y los abogados o por la demora en las citas por parte de los tribunales, hemos observado, pueden extenderse entre 3 y 10 meses.

«Yo quisiera mayor rapidez. Yo me fui un 6 de noviembre de mi casa; y a primeros de febrero fui al juzgado a preguntar porque mi abogada dice "no nos han citado". Y la chica que me atendió dice "sí, sí. Para julio tenemos las medidas provisionales". Me pilló en la época en la que estaba tan mal que me entró un soponcio, y me dice la chica "pero ¿qué pasa?". Y como un favor, revisó la agenda y me dio para el 14 de febrero. No se me olvidará en la vida. Pero, si no, a ver... yo parto de la premisa de que hay 3 menores fuera de su casa; nadie sabe cómo están esos menores» (Verónica).

A partir de ese momento, puede establecerse un acuerdo regulador o iniciarse un juicio contencioso. Como señala Hacker (2008), una parte importante de los casos se resuelven durante esta primera fase en las sombras de la ley entre las abogacías de las partes, mediante acuerdos reguladores. Es el momento de mayor actividad negociadora entre las abogacías de las partes, que suelen intercambiar varias propuestas. Si este proceso no arriba a un acuerdo, se va a juicio. En nuestros casos, seleccionados exprofeso por ser conflictivos, Dimitri nos cuenta el primer acuerdo, que luego recurre:

«Fue un acuerdo doloso, pero desde el primer momento, desde el día en que ella me traslada que quiere la separación, ya no se volvió a sentar conmigo a negociar o discutir nada. Todo lo hizo a través de los abogados. Todas las negociaciones del convenio regulador fueron a través de los abogados» (Dimitri).

En el caso de Fernando también se comienza negociando un acuerdo amistoso, pero no se llega al mismo y se pasa directamente al contencioso:

«Decidimos divorciarnos, al principio es como en todos los casos, maravilloso, te deja ver al niño, yo voy, te lo devuelvo, sin problemas. Pero el tema empieza a ponerse feo y siempre es por lo mismo, por temas econó- 
micos. Ella estaba tirando de cuenta, yo estaba tirando de cuenta, tú has tirado más, yo he tirado menos, yo retiré dinero, tú has retirado también, y el tema se emparda hasta el punto de que no me deja ver al niño. No me deja ver al niño, "pues no, no puedes", siempre con excusas, así estuve un año» (Fernando).

Cuando todavía no hay medidas establecidas judicialmente, cualquiera de los progenitores puede tomar decisiones unilaterales que aumentan la inseguridad en el otro. Con el conflicto abierto, uno no se fía del otro y, por lo que expresaron en las entrevistas, sus abogadas/os les suelen indicar que no retaceen las visitas del otro progenitor para no empeorar la resolución judicial, con lo que crece su sentimiento de indefensión. En el caso de Verónica, al malestar respecto de la seguridad de las criaturas mientras están con el padre se suma el temor frente a la amenaza de perderlos:

«Porque si tú no tienes medidas, entonces puede venir el padre, cogerlos y llevárselos, tiene el mismo derecho que yo. Creo que lo primero sería regular la situación de los menores. Porque cuando a mí me hacen el protocolo este que te hacen para ver el riesgo [violencia de género]; la obsesión suya, o la amenaza suya, era quitarme a mi hijo el pequeño. "Ya no lo vas a volver a ver". Yo cambié a mi hijo a la guardería, al lado de la comisaría de policía, por miedo a él» (Verónica).

Las problemáticas, además, son deslizantes y los acuerdos pueden ser satisfactorios en un momento dado y cuestionados en otro. Este es el caso de María: ella estaba viviendo una situación de violencia física y psicológica que nunca denunció y cuando la hija es testigo de una bofetada, decide el divorcio. No obstante, la niña, que tenía 4 años, le pide a la madre que acepte una custodia compartida y María accede:

«Aquello no fue un acuerdo. Fue que yo accedía a todo lo que él estaba dispuesto a dar; porque yo, en ese momento, lo que quería era pasar página y terminar. Ahora, claro, si fuera hoy, yo no tendría esa actitud» (María)

Los acuerdos entre las abogacías no son fruto de una mediación ya que las partes en conflicto están ausentes, es una negociación profesional extrajudicial. Entre los rituales de esta negociación, existe un último intento en el mismo juzgado, antes de entrar a la sala, conocido como «acuerdo en caliente». Algunas mujeres entrevistadas señalaron que accedieron a este tipo de acuerdos inducidas por los/as abogados/as, pero que luego se arrepintieron de ello. Una experta consultada señaló:

«La práctica generalizada de acuerdos en caliente por letrados/as debería evitarse, especialmente, en los casos de violencia de género, donde la celeridad del proceso de las Órdenes de Protección fuerza en muchas ocasiones a la adopción de acuerdos donde se tiene en cuenta más la practicidad de las personas adultas y no el interés superior de niños y niñas. Además, la mujer en esos momentos no se encuentra emocionalmente preparada para adoptar tranquilamente decisiones importantes que repercutirán en las relaciones familiares futuras con el padre maltratador» (abogada consultada mediante la técnica Delphi).

\section{Las medidas provisionales}

Dentro de los muros judiciales, cambia el escenario y los protagonismos. Los personajes principales son ahora el juez o jueza y la fiscalía. Paralelamente, los rituales judiciales quitan espacio a las abogacías y a las partes:

«Para mí el juicio es como un teatro. Tú vas allí y eres una actriz muy secundaria, ellos son los protagonistas, manejan el cotarro y tú tienes muy poco espacio. $Y$ a los abogados les dejan muy poco margen de maniobra, porque cuando empiezan un poco a cuestionar a la otra parte, por ambos sentidos, enseguida les cortan. Yo creo que si no estuvieran tampoco pasaría nada, porque es que cuando vas allí, como que ya está el pescado vendido" (Estela).

El procedimiento judicial comienza con la interposición de una demanda de separación o divorcio en un Juzgado de Familia o, si en la jurisdicción este tipo de tribunal no existe, en el Juzgado de Primera Instancia. Cuando se celebra la comparecencia para establecer medidas provisionales, las partes aportan pruebas y testimonios, pero normalmente la judicatura considera que no tiene los elementos suficientes para decidir, y pide al gabinete psicosocial unos informes periciales sobre la pareja y las/os menores. Si en el juzgado no existe gabinete, el informe se encarga a un/a perito judicial nombrado por el colegio profesional de psicología o de trabajo social ${ }^{4}$.

En la primera vista del juicio de divorcio, la judicatura suele optar por no modificar la situación previa de convivencia de los hijos e hijas, pudiendo establecer una custodia compartida si previamente existía alguna modalidad de reparto del tiempo con ambos progenitores. Excepcionalmente y porque juzgue que puede existir una situación de riesgo para los menores, puede modificar el régimen de convivencia previamente existente.

Como hemos dicho, el periodo que va desde que la pareja toma la decisión de separarse hasta que el juzgado determina las medidas provisionales, comporta un deterioro muy fuerte en las relaciones familiares cuando hay conflicto. La decisión de recurrir a tribunales es un elemento que potencia el malestar que hasta ese momento estaba más o menos larvado y postergado. Se sabe que comienza un periodo en que hay que desmontar todo lo que se construyó en común y esto puede implicar que el conflicto potencial entre quienes, hasta poco antes, integraban una pareja se

\footnotetext{
4 Una de las cuestiones señaladas por las personas expertas consultadas es la necesidad de mejorar la formación en género del personal de gabinetes, como así también, estabilizar las listas de los colegios profesionales.
} 
transforme en un enfrentamiento abierto. Ya no hay «contrato matrimonial» y tampoco pautas que rijan una cierta normalidad en las relaciones interpersonales entre la pareja ni con las criaturas. Por ello, aunque las medidas sean provisionales representan un alivio, porque es la primera ocasión en que se establecen unos criterios heterónomos que les permite salir de la anomia y recuperar parte de la tranquilidad perdida. Se podrá o no comulgar con el régimen de custodia provisional establecido, pero el cambio de situación es sustantivo. Se pasa, entonces, a una confrontación mediada por los tribunales, a los cuales se podrá apelar, pero también, con la sentencia en la mano, se podrá exigir a la expareja un comportamiento acorde. Como dijo una entrevistada «es mejor tener una mala sentencia, que no tener nada».

\section{El informe psicosocial y el dilema de las madres}

Los informes psicosociales fueron cuestionados por las personas entrevistadas, tanto mujeres como hombres. Una de las críticas recurrentes fue el hecho de que quien lo realiza solo recolecta información mediante una única entrevista con cada progenitor y criatura, lo que puede producir observaciones superficiales:

Los psicólogos parecen tener una bola de cristal, porque cuentan cosas de nuestra vida como si realmente la conocieran» (Luisa).

Inclusive pueden producirse sesgos, por ejemplo, puede señalarse una «disfunción parental» cuando lo que existe es un cuadro de estrés coyuntural derivado de la ruptura.

Las condiciones de trabajo de estos profesionales tampoco son óptimas. En los gabinetes psicosociales de los juzgados la mayoría es personal interino y quienes integran la lista de los colegios profesionales reciben unos modestos honorarios, unos $200 €$ por informe. La gran paradoja es que se les atribuya, de un lado, un gran poder y reconocimiento, ya que del informe colegirá en gran medida la decisión judicial; pero, por otro lado, unos magros ingresos. Cabe agregar, no obstante, que el prestigio y poder de los/as profesionales de la psicología y del trabajo social son muy inferiores a los que detenta la judicatura. Hacker (2008) considera que estos terapeutas ajustan sus ritmos y esfuerzos a los plazos judiciales y a los presupuestos $y$, en algunos casos, aunque debieran profundizar, pasan por alto muchas cuestiones, presionados por los tiempos con los que hay que realizar los informes. Lo que está en juego, aunque no se reconozca, es mantenerse en plantilla y responder en tiempo y forma a las demandas, dando una cobertura científica a todo el proceso judicial.

El informe psicosocial -en el que queda reflejada la situación de las exparejas y sus criaturas- es un relato compuesto por indicadores de las pruebas-test y del recorte de las narrativas de los progenitores y menores elaborado por los/as peritos/as. De su lectura, hemos podido observar una cierta estandarización de los informes resultante de un proceso de filtrado operado, primero, por los/as profesionales y luego, por los jueces y juezas que toman retazos cuando desarrollan sus argumentaciones. Este troquelado conlleva la pérdida de muchos detalles y aumenta los márgenes de discrecionalidad en la elaboración de las sentencias. Rodríguez-Llamas (2020), en su análisis de sentencias judiciales, observó que frente a situaciones similares distintos jueces tomaron decisiones contrapuestas. Las piezas son encajadas unas con otras, interviniendo las propias valoraciones para conformar la decisión judicial (Fineman, 1988; Cohen y Segal, 2000).

Por ello, es importante la formación en género, tal como nos fue señalado por una Técnica de un Punto de Encuentro Familiar:

«Yo añadiría que en las universidades se impartan obligatoriamente conocimientos de violencia de género en justicia, psicología, medicina y magisterio. Yo he hablado con jueces que en privado me han dicho "De ley, nadie va a enseñar a un juez". Cuando eres una persona que trabaja constantemente con casos de violencia, puedes tender a verlos todos iguales, y eso es un problema. Es muy difícil obligar a un juez a la formación» (entrevista a técnica).

Además, las mujeres que viven violencia, pero no la denunciaron, nos contaron que en los peritajes ellas se encontraban en la situación que Elizabeth et al. (2010) han caracterizado como el dilema de las madres. Porque cuando tienen que informar sobre las consecuencias negativas que ellas observan luego de las visitas de sus hijos e hijas a su padre maltratador, ellas tienen miedo a no ser creídas. Temen ser construidas como hostiles y señalan que sus declaraciones repercutan de forma negativa para ellas en los informes psicológicos $y$, por lo tanto, en el resultado de los juicios. Harrison (2008) plantea ¿son las mujeres implacablemente hostiles o apropiadamente protectoras? Ellas necesitan contar lo vivido para proteger a sus criaturas de una posible custodia compartida, pero sienten que el medio judicial no está preparado para recibir este tipo de testimonio.

«Yo veía negligencias en los cuidados: falta de higiene, muchísima. Una vez vi un quemazo de un cigarro, por negligencia, o sea, no digo que le quemara, pero estaría fumando... Entonces se lo dije, digo: "oye, qué es esto". Y él contesta: "Estaba con unos amigos y ha venido corriendo y se ha quemado".Ya, tío, pero es un quemazo de un cigarro y ella vino llorando» (Celia).

«Desde hace un mes [el niño tiene 4 años] ya lo tiene más asumido [ir a pernoctar a lo del padre] Pero me pregunta: “¿Hoy duermo aquí contigo?” Algún amigo me ha dicho: "bueno, a él le dirá lo mismo, porque los niños son muy manipuladores". Pero que tu hijo te diga entre lágrimas "mamá no me pongas el calzoncillo para ir a casa de papá, ponme el pañal porque papá dice que es que si no, me hago pis en el suelo". ¡Con lo que costó! Estuvo usando pañales hasta los tres años. Y claro, el otro le hacía el chantaje de "Me manchas la cama y..." Las típicas cosas que me decía a mí también» (Virginia). 
Las dificultades para la evaluación son muchas, también son de tipo técnico vinculadas a la validez de los test que se aplican (Arce et al., 2013) que, además, no están adaptados para captar las relaciones asimétricas de género tan importantes en el conflicto familiar. Por lo tanto, las evaluaciones debieran realizarse por personal muy calificado, probablemente con intervención de varios profesionales, de modo tal de controlar posibles sesgos personales, y ser realizados con el tiempo suficiente como para recabar información amplia de la familia y de los ámbitos que se considere relevantes en cada caso (escuela, médico/a, escuela deportiva, etcétera).

\section{Las medidas definitivas}

La celebración del juicio de medidas definitivas suele demorarse entre 6 u 8 meses desde las medidas provisionales. Se ejecuta en una hora o dos, tiempo en el cual se producen las interpelaciones. Algunos de los elementos destacados por las personas entrevistadas en esta etapa han sido: los déficits que plantean los rituales judiciales, la necesidad de escucha a los niños y niñas y el doble rasero que se produce en torno a la capacidad para cuidar de las madres y padres.

Respecto de los rituales judiciales se señaló que dejan poco margen para que las abogacías de las partes puedan incorporar algunas pruebas adicionales en medio de interrogatorios que ya están pautados. Los integrantes de la expareja tampoco pueden realizar aclaraciones que les surjan en el momento, ni desmontar posibles prejuicios o dar su versión sobre los procesos vividos. Solo si se les consulta pueden contar retazos, y los testimonios se quedan en la superficie de los problemas. Las mujeres entrevistadas nos transmitieron su sensación de tener una presencia fantasmagórica (estar ahí, pero no ser vistas por nadie). Lo que se agrava cuando el conflicto es recurrente, porque en cada juicio deben ajustarse a lo que se les pregunte en la nueva situación, como si fueran situaciones discretas, separadas, como si no formaran parte de una misma historia, su historia.

Los rituales no reservan momento alguno para que madres y padres se puedan expresar con una cierta libertad. Porque una cosa es que la expareja no haya podido resolver por su cuenta sus desavenencias y traslade el pleito a la justicia (y, por lo tanto, su poder de decidir) y otra que la cesión sea total y apenas tenga voz, y posibilidad de ser sujetos, en algo tan transcendente.

Como ya hemos mencionado, los informes psicosociales tienen una importancia capital en esta etapa. Siguiendo a Carol Gilligan (1985) podemos decir que los informes incluyen las orientaciones éticas de quienes los elaboran y utilizan. En ellos predomina la visión ética masculina cuya orientación está dirigida a una concepción abstracta de la justicia y los derechos, mientras que las mujeres tienen una orientación ética que prioriza el cuidado y la responsabili- dad. Fascioli (2010), sobre esta base, señala que existe en la judicatura un paradigma que «valora la imparcialidad, el mirar al otro como otro genérico, para no dejarse influir por la simpatía o el sentimiento. La adopción de este punto de vista imparcial hace suponer que todas las personas racionales coincidirán en la solución de un problema moral. Las mujeres, orientadas en cambio por una ética del cuidado, tienen juicios morales más contextuales e inmersos en los detalles de las situaciones, y tienden a adoptar el punto de vista del "otro concreto" -sus necesidades, más allá de sus derechos formales-. Sus juicios involucran sentimientos y una concepción global» (Fascioli, 2010: 44). El predominio de la orientación ética masculina es independiente del sexo, porque como señala Hunter (2015), las juezas se ven impulsadas a adoptar la práctica jurídica dominante para no ser marginadas o excluidas de la carrera judicial.

En los informes psicosociales se llegan a incluir recomendaciones sobre el tipo de custodia que se debería adoptar y esto se realiza pese a que la decisión sobre la custodia es una competencia exclusiva de la judicatura. Todo se agrava porque las partes suelen recibir los informes poco antes del juicio y no tienen opciones de intentar vetar su contenido. En la práctica son inobjetables, salvo con otro juicio, lo que entraña costo emocional y económico.

En esta fase, el menor protagonismo es el de los niños, niñas y adolescentes que son objeto (y no sujetos) de la disputa. En la retórica judicial aparece repetidamente el principio del "interés superior del menor", pero la creencia de que su voluntad puede estar manipulada, les priva de su derecho a tener voz propia. La jurisprudencia señala que su voluntad, lógicamente, no es vinculante, pero de nuestro análisis surge la observación de que se descuida su bienestar cuando la judicatura no instrumenta los medios para averiguar por qué ese menor no desea ver a un progenitor. En ocasiones, se dicta una custodia compartida o una visita que es forzosa para esa criatura, colocándola en una situación muy penosa. En el caso de los Puntos de Encuentro Familiar, desde 2016, se está cambiando el enfoque para respetar la voluntad del menor que no desea tener contacto con su progenitor. No obstante, es una cuestión que debería regularse y no quedar a merced de la voluntad privada de la empresa que gestiona el recurso social.

Las niñas, niños y adolescentes son los grandes ausentes, en general, en los procesos de toma de decisiones: en las familias, en los ámbitos profesionales de intervención y en la decisión judicial. Esto, según una experta en psicología del Centro Mujer 24 horas, produce una gran ansiedad en ellos y en ellas, inclusive, enferman. No saben qué les sucederá y nadie les informa, ni a qué tendrán que enfrentarse cuando van a sede judicial, no se les prepara. No existe un servicio de información exclusivo para ellos y ellas.

«A mi hijo pequeño lo he tenido 3 meses en silla de ruedas, y un mes y pico con muletas. Físicamente no tenía nada; le han hecho resonancias, ha estado ingresado... Y el único punto de inflexión, es cuando empezó a irse a dormir a casa del padre. Un día salió del cole y al día siguiente no pudo andar. El dolor era real, de noche y de día lloraba. Pero la pediatra me dijo "es que no hay nada". No tenía nada que le impida caminar. Ahora ya 
está bien. Ha estado la psicóloga del Punto de Encuentro Familiar con él y parece que le cambió el chip. Que yo no digo que le haga nada [el padre], y no quiero enfocarlo por ahí, porque si no, me volvería loca, pero ir a dormir con el padre fue lo único que en ese momento coincidió» (Verónica).

De la lectura de algunas sentencias e informes psicosociales, hemos observado que en ocasiones se hace referencia al Síndrome de Alienación Parental (SAP). Su escasa mención probablemente se deba a que la Audiencia Provincial de Navarra sentó jurisprudencia, indicando que este supuesto síndrome no tiene ninguna base científica $y$, por lo tanto, no debiera utilizarse como argumento en las sentencias judiciales. No obstante, se señala que el niño o la niña está instrumentalizado, mediatizado o manipulado, cuestionando sus razones o quitando importancia a sus opiniones y deseos. No se hace mención del SAP, pero estas expresiones cumplen la misma función: reducir la capacidad de influencia del menor, acusando, a su vez, a la madre.

Otro aspecto que la legislación establece para decidir un régimen de custodia es la dispensa de cuidados realizada por ambos progenitores antes de la separación. Por ello, en muchas sentencias observamos la expresión "la capacidad del progenitor para cuidar". Esta muletilla es utilizada en la judicatura de forma diferente según recaiga en un padre o en una madre. A ello se le denomina sesgo de género (Eichler, 1991; Díaz, 2015). En el caso de ellos es una capacidad potencial e implica una segunda oportunidad. En el caso de ellas, se valora el cuidado efectivamente prestado y por el cual se las juzgará como buenas o malas madres. Algunas de las personas expertas consultadas señalaron:

a. «Por las propias creencias sociales, se piensa que la madre tiene una mayor capacidad de cuidado que los padres sin que ello sorprendentemente repercuta especialmente en la asignación de la guarda y custodia materna en algunos de los juzgados, ya que priorizan cada vez en mayor medida la custodia compartida con independencia del interés superior del menor. Es una realidad, ello se debe a la falta de perspectiva de género de la mayoría de jueces/as y fiscales» (Técnica del Punto de Encuentro Familiar).

b. «Es indudable que los y las jueces, como el resto de las personas de nuestra sociedad, están condicionados por la ideología patriarcal o ideología de supremacía masculina y son mucho más laxos a la hora de evaluar la capacidad de cuidados en los hombres que en las mujeres. Dan por hecho que los cuidados corresponden a las mujeres y que los padres también lo pueden hacer, aunque nunca lo hayan hecho antes de la ruptura» (abogada).

En ambas opiniones se indica un doble rasero (Eichler, 1991), porque por un lado se considera a las mujeres como titulares de los cuidados, pero al final, los fallos pueden favorecer igual a los hombres, porque se entiende que las labores de crianza son asumibles por cualquiera. No se perciben ni se ponen en valor las desigualdades de género previas, se produce una especie de des-generización del cuidado, olvidando la experiencia histórica y los datos objetivos que en cada caso van indicando que los cuidados no son equiparables (Natalier, 2018). También, en la decisión judicial pesa demasiado la presencia o no de apoyo familiar. La colaboración de abuelas o nuevas parejas debería ser accidental y un dato secundario porque lo que está en juego es el cuidado que pueden prestar los progenitores. Luego está el contacto, que puede lograrse también mediante un amplio régimen de visitas. Y si los derechos adultos de custodia confrontan con los derechos de la infancia a ser cuidados, se debieran priorizar éstos últimos, logrando un acuerdo en el que, gracias también a las visitas pautadas, se puedan combinar las tres C: custodia, cuidado y contacto.

\section{La recurrencia del conflicto}

El conflicto puede ser positivo porque es la ocasión de replanteo de unas normas de convivencia. O puede, como en los casos analizados, que se inicie un periplo infinito, kafkiano, que se instala de forma crónica entre la expareja y que las lleva recurrentemente a los juzgados, involucrando a sus hijos e hijas. En las situaciones de violencia de género está presente la estrategia masculina de seguir incidiendo en la vida de la mujer y castigarla por haber optado por la separación y salir, de este modo, de su control.

Por ello, las sentencias judiciales no resuelven un conflicto que en el fondo no es exclusivamente económico ni tampoco gira solo en torno a la custodia de las criaturas, aunque formal y oficialmente éstos sean los temas en disputa. Porque lo que se añade es un conflicto emocional muy profundo que no se sabe cómo gestionar. Se han roto los canales de comunicación entre dos personas que antes eran como una (una pareja, un matrimonio, un hogar, un amor), y entran en un bucle en el que ya no se reconocen y se instala un litigio cuyo objetivo es el litigio mismo. Este conflicto emocional aparece mezclado con temas económicos y con toda una serie de pequeñas o grandes decisiones del pasado y presente. $Y$, como vivimos en una sociedad con asimetrías de género, en las circunstancias analizadas y bajo el argumento de ser titular de la patria potestad, hemos observado que los padres suelen buscar una injerencia en decisiones de la vida cotidiana de las criaturas, de las cuales, hasta ese momento, estaban ausentes.

Hay una gran conflictividad alrededor de la pensión alimenticia. Como señala Zelizer (2011), los economistas clásicos se equivocaron al señalar sin más que el dinero es el equivalente general de las mercancías. Ella observa que hay dineros que tienen un poder simbólico especial. Como la moneda de $2 €$ que separamos en una lata para compras o necesidades especiales. La pensión "de los niños/as" no es cualquier dinero. Es un dinero que implica una transferencia de un progenitor a otro para cubrir los gastos de las criaturas que se tienen en común y, lo que observamos, es que el progenitor que paga se siente con derecho a controlar en qué se gasta: 
Todo lo que me ha pasado a mí ha sido por mirar por mi hijo y por su bien. Pero ves que le das la manutención y que casi siempre el dinero es para pagar luz y agua, $y$ tu hijo no lleva unas zapatillas nuevas en tres meses o ropa nueva. En la sentencia me acusó de que me había llevado dinero, pero vamos, en todos los juicios que he tenido con ella lo ha intentado meter por medio, para ver si se llevaba algo. Económicamente siempre pidiendo más y más y más y lo que queda [de tiempo], porque esto no se ha acabado. Ahora mismo estoy... Lo último que tuvimos, que ha recurrido, y estoy pagando el último recurso, estoy esperando (Bernardo).

Varias mujeres nos han señalado que sus exparejas camuflan sus ingresos para disminuir la pensión, aunque luego lo compensen con regalos directos a sus hijos/as. Ellos quieren seguir siendo sostén de sus hijos, pero temen que ellas quieran el dinero para ellas:

Al final, le dije, yo ya no te voy a dar un duro a ti [a su exmujer], tu dime lo que tengo que pagar y lo pagaré directamente allí, mi parte. Porque ya paso. Mandarme un recibo, no me manda recibos. Me manda fotos por WhatsApp, que ves lo que ves. Entonces yo le dije, que esto puedo hacerlo así. Por supuesto, lo consulté con mi abogado. Tampoco es que pueda hacerlo así... Y ellos que hagan una doble factura, tu mitad por una parte y la suya por la otra (Juan).

Cuando hay custodia exclusiva materna, ellos han de pasar una pensión de gastos corrientes para sus criaturas (comida, ropa, útiles escolares). Aunque mantengan el rol de sostén económico (que en las sentencias suele atribuirse a ambos si previamente había doble ingreso), pierden presencia y poder real sobre las decisiones cotidianas que se toman en torno a la vida de sus hijos e hijas, aunque mantengan (porque casi nunca se pierde) la patria potestad (compartida con sus exesposas). La paga o -en los casos de custodia compartida- el presupuesto en común, pueden ser medios de control cuando no se asumen como simples contribuciones dinerarias sino que se exige un detalle de los gastos o se cuestionan algunos de ellos, inclusive, aunque no se conozca si realmente el dinero del gasto en cuestión salió de la pensión.

En varias entrevistas realizadas a hombres aparece la idea de que la pensión de las criaturas es un beneficio para la mujer. Esta sensación se acrecienta cuando hay nuevas parejas, porque surge el malestar del padre desplazado. Quizás ello explique el hecho de que la mayor parte de las custodias compartidas son solicitadas por los padres.

Kristin Natalier habla de "abuso económico posterior a la separación relacionado con la manutención de los hijos, relacionado con el orden social de género, al que refleja y reproduce" (2018: 122). Consiste en una limitación de los pagos destinada a recuperar una parte del control perdido en un espacio social al que ya no pertenecen, el de la nueva familia que integra la madre, las criaturas y, quizás, otros nuevos integrantes.

En nuestros casos, hemos observado que se libra una "guerra de desgaste», invisible, encuadrada siempre dentro de unos límites, para que se mantenga dentro del espa- cio de lo cotidiano. Son comunes también las disputas en torno a los gastos extraordinarios, desde gastos médicos o dentales hasta actividades sociales o lúdico-deportivoculturales. Cuando se acumulan demasiadas tensiones, se pasa del abuso económico larvado al conflicto abierto en medio judicial. Se producen juegos, se sabe hasta dónde tensar, luego aflojar, conciliar, y volver a tensar, hasta que la situación no da para más y termina con una querella en los juzgados.

«He conseguido que se regule, pero los incumplimientos han seguido dándose, el miedo sigue, la pensión, a día de hoy, falta el mes de agosto y $200 €$ que no nos ha pagado. Quiero decir, pero llega un momento que sólo quiero estar tranquila, ya, si no vienes [a recoger al niño], si me avisas en el día ya hago yo los cambios, aunque no me toque y él debiera recurrir a su propia gente, es que entrar en pequeñas cosas a nivel judicial es desgastante» (Estela).

Él incumple parte del trato y Estela se siente intimidada. Él es físicamente muy grande y la amenaza verbalmente. Puede volver a recurrir a la justicia, pero ella dice: «es desgastante». Estela prefiere buscar arreglos informales, aunque sean provisorios. La situación descrita se repitió en varias de las entrevistas.

La sentencia judicial es valorada por las mujeres, porque es una norma objetiva establecida por una autoridad que les permite persuadir a sus excónyuges para que sigan unas regulaciones heterónomas establecidas. Y si no las cumplen, pueden volver a recurrir a la justicia. La otra parte sabe que el costo que tiene para ella obligarle a cumplir el acuerdo es alto, porque implica una denuncia, «con los tiempos de la justicia», y el estrés que genera verse incursa en procesos judiciales de forma recurrente. Entre lo establecido por la norma y su cumplimiento, se producen juegos de poder, y estos son dependientes de lo que se pone en juego al cumplir o no cumplir. Hay un costo emocional y económico «al hacer la vista gorda» y hay un costo emocional y de tiempo «al denunciar el incumplimiento».

En los casos en que hay violencia de género, Boyd (2010) analiza las ambigüedades que atraviesan las madres, y señala que entre los factores que sopesan para quedarse o irse, para denunciar o no hacerlo, juega un papel importante su responsabilidad para proteger a sus hijos/ as. Pero luego sus experiencias con la justicia pueden revictimizarlas. Les resulta arduo transitar entre juzgados de distintos fueros: penal y familiar, sin coordinación, como para comprender el riesgo del que intentan salir, ellas y sus criaturas. Watson y Ancis indican "que una mujer haya dejado una relación abusiva no significa que el abuso haya remitido" (2013: 167). En una relación donde hay maltrato, el conflicto es una constante, porque a través de éste se mantiene el control coercitivo, que Samantha Jeffries define como «un patrón de tácticas dominantes intencionales empleadas por los perpetradores masculinos con la intención de gobernar los pensamientos, creencias o conducta de sus víctimas femeninas y/o castigarlas por resistirse a su regulación» (2016:1). Por ello, y para evitar consecuencias negativas como el apego inseguro en los niños y niñas más pequeños habría que brindar apoyo a las madres que 
sufren violencia, cuanto antes mejor (McIntosh et al. 2019). Es necesario intervenir para que no se produzcan unas consecuencias tan extensas en el tiempo, como el círculo vicioso del abuso económico y el acoso de custodia (Elizabeth, 2017).

Las madres, al pasar más tiempo con sus criaturas, toman decisiones sin consulta, por falta de tiempo o por las dificultades de comunicación con su expareja. Los padres lo resienten como menoscabo de su patria potestad o como una limitación de su patriarcal poder de decisión. La maternidad se encuentra amenazada porque en casi todas las decisiones que toman son cuestionadas frente a las criaturas por padres que ahora se involucran y opinan sobre pequeñas cuestiones cotidianas: si pueden asistir o no a una actividad, cumpleaños, el modo de realizar las comuniones, campamentos, vacaciones, dentista, etc.

En los peores casos, envían correos electrónicos con acusaciones y llamadas a cualquier hora. Y correos electrónicos o WhatsApp a los hijos e hijas con chantaje emocional que producen mucho sufrimiento. Otra de las formas en que se expresa el cuestionamiento de la autoridad maternal es a través de cambios de parecer sobre cualquier cosa, pero, sobre todo, en torno a acuerdos informales para ajustar el régimen de visitas a situaciones excepcionales que se puedan producir o los relacionados con vacaciones o fiestas importantes.

El daño psicológico no es visible de forma inmediata como sí lo es un daño físico. Si bien hemos descrito aquí la forma en que aparece en la etapa post divorcio, sus raíces hay que ubicarlas bastante más atrás. Y esto es independiente del resultado de la sentencia judicial, ya que las «maternidades amenazadas» son una situación que acompaña tanto a las custodias exclusivas maternas como a las custodias compartidas. Porque este fenómeno está relacionado con el ejercicio abusivo de la patria potestad, que rara vez se suspende tras del divorcio, aunque exista violencia. Las maternidades amenazadas son el resultado de un constante cuestionamiento, antes, durante y con posterioridad al proceso judicial, mediante la disputa por la custodia compartida, las presiones económicas, el cuestionamiento sobre todo tipo de micro-decisiones y la limitación del contacto mientras están en la casa del padre.

En definitiva, cuidar de los hijos entraña todo tipo de dificultades, en múltiples dimensiones, porque el cuidado es a la vez físico, afectivo, psicológico, intelectual y social, como mínimo. Y los juegos de poder implícitos pueden dificultar el cuidado y el bienestar de las criaturas.

\section{Conclusiones}

Los tiempos de la justicia y los tiempos de las personas que atraviesan rupturas familiares parecen no coincidir. Hemos observado que el periodo de mayor incertidumbre y malestar se produce al inicio, entre la comunicación del divorcio a la pareja y la celebración de medidas provisionales, por lo que las personas entrevistadas plantearon la necesidad de una aceleración de los plazos judiciales. En este periodo de anomia pre-judicial toman protagonismo las abogacías de las partes cuya actuación también merece ser revisada, tanto porque incrementa la desconfianza entre la expareja y se judicializa sus vidas, como porque les presionan para concertar acuerdos regulatorios. El conflicto es deslizante, porque puede permitir alcanzar un acuerdo bien establecido o derivar, pronto o tarde, en un conflicto abierto.

La sentencia judicial es una norma que pacifica solo en parte unas relaciones deterioradas porque, hemos visto, existen grietas a través de las cuales se cuelan relaciones de poder. La patria potestad puede ser utilizada como un recurso para intervenir de forma dolosa en las decisiones que la expareja toma sobre las criaturas, generando un verdadero acoso sobre pequeñas decisiones de la vida cotidiana que son permanentemente sometidas al arbitrio y a la disputa entre los progenitores.

En este artículo he prestado atención a los círculos viciosos que se producen en torno a la pensión de alimentos y a las decisiones cotidianas. Se trata de juegos que esconden y refuerzan relaciones de género asimétricas, que intentan escapar a las regulaciones formales. Por ello son juegos fronterizos, tensan sin romper del todo las normas. Un retraso en la pensión de alimentos puede no ser considerado un impago, está ahí, en la frontera. Igual que intervenir en las decisiones sobre los hijos e hijas, ¿no es acaso una forma de mostrar interés? Pero esa intervención puede devenir en una desautorización permanente, como la que hemos observado, cuando lo que se busca es el conflicto por el conflicto mismo.

En los casos analizados donde el conflicto es permanente, se producen diferentes manifestaciones de violencia, explícitas e implícitas, que deben ser tenida en cuenta por los tribunales y gabinetes psicosociales. Por ello, al pensar en qué tipo de régimen responde mejor al interés superior del menor no es posible hacerlo de forma categórica, instaurando un principio general. Es necesario no solo oír, sino escuchar a los menores, considerar sus inquietudes y necesidades, al mismo tiempo que establecer mecanismos de seguimiento del cumplimiento de la sentencia durante un periodo prolongado. También, debería revisarse el procedimiento relacionado con los informes psicosociales -que son el elemento básico que da legitimidad a la sentencia judicial- tanto sus modos de realización como los principios sobre los que se fundamentan.

Otro elemento que hemos observado es cuando las madres son inducidas al silencio, ya que auto-limitan sus relatos por temor a ser construidas como hostiles. Esta inducción sutil se deriva de la presencia de estereotipos de género en las praxis judiciales. Además del silencio, se produce un troquelado de la vida de las personas en procesos de divorcio conflictivo durante el proceso de producción de la sentencia (ejecutado por profesionales terapéuticos y de la judicatura). Ello nos lleva a proponer que se establezcan espacios durante el proceso judicial que permitan una mayor expresión por parte de los progenitores y las criaturas, sobre todo porque no se juzgan hechos puntuales sino trayectorias que abarcan muchos años. Las historias no pueden ser contadas mediante respuestas cortas y necesitan de una comprensión holística profunda. 
También, a lo largo del estudio se puso en evidencia la necesidad de formación de los y las profesionales y una adecuación de las herramientas de valoración, incorporando la perspectiva de género con el fin de poder comprender y tener en cuenta el trasfondo que esconde cada situación escapando de la hegemónica mirada androcéntrica y patriarcal. Con el escenario descrito, no hacerlo, genera violencia institucional.

Finalmente, cabe señalar que existen presunciones culturales y valores muy potentes en torno a la institución familiar, pero, como señala Gilmore (2006), aunque para el bienestar del niño/a es importante mantener una relación con ambos padres, ya sea a través del contacto con un padre no residente o mediante un acuerdo de residencia compartida, también existe evidencia de investigación en contrario, porque los tribunales no pueden partir de una presunción per se de contacto ya que la complejidad de las situaciones familiares debe ser tenida en cuenta. El contacto con un progenitor no residente puede ser beneficioso, pero también puede estar asociado a riesgos para el bienestar infantil.

\section{Bibliografía}

ALONSO, L. E. (2013): "La sociohermenéutica como programa de investigación en sociología", Arbor, 189 (761), a035. doi: http://dx.doi. org/10.3989/arbor.2013.761n3003

ARCE, Ramón; FARIÑA, Francisca y SEIJO, Dolores (2013): "¿Disimulan los progenitores en litigio por la custodia en el 16 PF-5?", Anuario de Psicología Jurídica, 23, pp. 25-30.

BOYD, Susan B. (2010): “Autonomy for Mothers? Relational Theory and Parenting Apart", Feminist Legal Studies, 18, pp. 137-158

COHEN, Orna y SEGAL-ENGELCHIN, Dorit (2000): "Suzi and Mr. S.: Gender Role Stereotyping in Social Workers. Court Reports in Custody and Access Cases", Smith College Studies in Social Work, 70, pp. 475-500.

DÍAZ MARTíNEZ, Capitolina (2015): "La perspectiva de género en investigación social", en Manuel García Ferrando et al. (eds.), El análisis de la realidad social: métodos y técnicas de investigación. Madrid, Alianza, pp. 176-201.

EICHLER, Margrit (1991): Nonsexist research methods: A practical guide. London, Routledge.

ELIZABETH, Vivienne (2017): “Custody Stalking: A Mechanism of Coercively Controlling Mothers Following Separation", Feminist Legal Studies, 25, pp. 185-201. Doi: https://doi.org/10.1007/s10691-0179349-9

ELIZABETH, Vivienne; GAVEY, Nicola y TOLMIE, Julia (2010): "Between a rock and a hard place: Resident mothers and the moral dilemmas they face during custody disputes", Feminist Legal Studies, 18 (3), pp. 253-274.

FASCIOLI, Ana (2010): "Ética del cuidado y ética de la justicia en la teoría moral de Carol Gilligan", Revista Actio, 12, pp. 41-57.

FINEMAN, A. Martha (1988): "Dominant Discourse, Professional Language, and Legal Change in Child Custody Decision-making", Harvard Law Review, 101, pp. 727-774.

GILLIGAN, Carol (1985): La moral y la teoría. Psicología del desarrollo femenino. México, FCE.

GILMORE, Stephen (2006): "Contact/shared residence and child wellbeing: research evidence and its implications for legal decision-making", International Journal of Law, Policy and the Family, 20 (3), pp.
344-365. Doi: https://doi.org/10.1093/lawfam/ebl016.

GLASER, Barney G. y STRAUSS, Anselm (1967): The Discovery of Grounded Theory. Strategies for Qualitative Research. Chicago, Aldine.

HACKER, Daphna (2008): "A legal field in action: the case of divorce arrangements in Israel", International Journal of Law in Context, 4 (1), pp. 1-33. Doi: https://doi.org/10.1017/S1744552308001018.

HARRISON, Christine (2008): "Implacably hostile or appropriately protective? Women managing child contact in the context of domestic violence", Violence Against Women, 14, pp. 381-405.

HUNTER, Rosemary (2015): "More than just a different face? Judicial diversity and decision-making", Current legal problems, 68 (1), pp. 119-141. Doi: https://doi.org/10.1093/clp/cuv001.

JABBAZ CHURBA, Marcela y Capitolina Díaz Martínez (coords.) (2020): Menores en disputa: custodia, visitas y patria potestad en la Comunidad Valenciana. Valencia, Tirant lo Blanch.

JEFFRIES, Samantha (2016): "In the Best Interests of the Abuser: Coercive Control, Child Custody Proceedings and the "Expert" Assessments That Guide Judicial Determinations", Laws, 5 (1), 14. Doi: https://doi. org/10.3390/laws5010014.

JICK, Tobd (1979): “Mixing Qualitative and Quantitative Methods: Triangulation in Action, Administrative Science Quartely, 24 (4), pp. 602611. Doi: https://doi.org/10.2307/2392366.

MCINTOSH, Jennifer; TAN, Evelyn; LEVENDOSKY, Alytia y HOLTZWORTHMUNROE, Amy (2019): "Mothers' experience of intimate partner violence and subsequent offspring attachment security ages 1-5 years: A meta-analysis", Trauma, Violence, \& Abuse, 21, pp. 1-15. Doi: https://doi.org/10.1177/1524838019888560.

MINISTERIO DE IGUALDAD (2019): Macroencuesta de violencia contra la mujer. https:/violenciagenero.igualdad.gob.es/violenciaEnCifras/ macroencuesta2015/pdf/Macroencuesta_2019_estudio_investigacion.pdf.

MORGAN, Gareth (1983): Beyond method: Strategies for social research. Los Ángeles, Sage.

NATALIER, Kristin (2018): "State Facilitated Economic Abuse: A Structural Analysis of Men Deliberately Withholding Child Support", Feminist Legal Studies, 26, pp. 121-140. Doi: https://doi.org/10.1007/s10691018-9376-1.

RODRÍGUEZ-LLAMAS, Sonia (2020): “Lo que dice el poder judicial sobre la guarda y custodia", en Marcela Jabbaz Churba y Capitolina Díaz Martínez (coords.), Menores en disputa: custodia, visitas y patria potestad en la Comunidad Valenciana. Valencia, Tirant lo Blanch, pp. 199-223.

WATSON, Laurel B. y Ancis, Julie R. (2013): "Power and Control in the Legal System: From Marriage/Relationship to Divorce and Custody", Violence Against Women, 19 (2), pp. 166 -186. Doi: https://doi. org/10.1177/1077801213478027.

ZELIZER, Viviana (2011): El significado social del dinero. Buenos Aires, Fondo de Cultura Económica. 